\section{Dr. Tselios, et al reply}

\section{To the Editor:}

We thank Bachmeyer, et $a l^{1}$ for their views on our recent $\operatorname{article}^{2}$ on mycophenolate mofetil (MMF) in refractory nonrenal manifestations of systemic lupus erythematosus (SLE). Concerning their observations on the definition of skin lesions, we have clearly indicated in the Materials and Methods section that the main indication for MMF was retrieved from the respective Systemic Lupus Erythematosus Disease Activity Index 2000 (SLEDAI-2K) element that was present at that particular date. The cutaneous variable of this index is defined in the SLEDAI-2K glossary as inflammatory type rash and includes acute, subacute, or chronic types of cutaneous lupus erythematosus (CLE). Because SLEDAI-2K was not designed to identify fluctuating activity within a particular organ system, we only reported the patients who achieved complete resolution by the end of 6 and 12 months, and not those who had a partial response. The Cutaneous Lupus Erythematosus Disease Area and Severity Index (CLASI), mainly used in randomized clinical trials, was not routinely documented in our cohort; hence, we could not provide reliable data on the evolution of such lesions (and thus, they were not reported in our article). Nevertheless, we agree that cutaneous lupus is highly diverse in clinical presentation and consequently in pathogenesis, as we mention in the Discussion section.

We also agree that hydroxychloroquine (HCQ) is the cornerstone of therapy, not only for CLE, but also for virtually all patients with lupus in the absence of specific contraindications. However, the statement that HCQ blood concentration should be monitored in daily practice to guide therapy should be treated with skepticism. Apart from the limited availability of the assay, a rather wide concentration range (208-3316 ng/ml, high-performance liquid chromatography) was recently reported in 509 patients treated with stable doses of HCQ $(400 \mathrm{mg} / \mathrm{day})^{3}$. In addition, there was no difference with regard to their global disease activity while patients with low HCQ concentration were taking corticosteroids significantly less frequently. Further, the authors reported a median HCQ concentration of $917 \mathrm{ng} / \mathrm{ml}$ upon which they based the categorization of their patients to low and high concentration groups. Another recent study reported that only $12 \%$ of 276 patients achieved therapeutic levels (defined as $>500 \mathrm{ng} / \mathrm{ml}$, mass spectrometry) whereas $77 \%$ of the patients were in the subtherapeutic range (10-500 $\mathrm{ng} / \mathrm{ml})^{4}$. There was no difference in new disease flares, time-adjusted disease activity, and new organ damage between patients with extremely low $(<10$ $\mathrm{ng} / \mathrm{ml}$ ), subtherapeutic, or therapeutic HCQ concentration after a followup of 3 years. In the quoted study of Chasset, et al, an increase of HCQ dose to $600-800 \mathrm{mg} /$ day in 32 patients (to achieve a serum concentration $>750$ $\mathrm{ng} / \mathrm{ml}$ ) led to $20 \%$ improvement in the CLASI after 3-6 months ${ }^{5}$. Among 18 patients with sustained response (taking a retinal-toxic dose of $9.2 \mathrm{mg} / \mathrm{kg}$ for a median of $16 \mathrm{mos}$ ), 11 relapsed after HCQ was decreased to the usual $400 \mathrm{mg} /$ day. The discrepancies concerning HCQ blood concentration come as no surprise because the drug has long and variable plasma half-life (40-60 days) and a high volume of distribution $(44,0001)^{6}$; it is not known whether tissue-deposited drug is still biologically active or can be released into circulation under certain circumstances.

Concerning the comment of Bachmeyer, et $a l^{1}$ on the low level of antimalarial usage $(80 \%)$ in our cohort, we state that similar levels have been reported in other large registries such as the RELESSER group with $83 \%$ in 4024 patients $^{7}$, while lower numbers were described in inception cohorts, such as the Systemic Lupus International Collaborating Clinics cohort, with $67 \%$ in 1722 patients $^{8}$. Ocular and gastrointestinal toxicity along with intolerance in a certain number of patients may account for this

According to our results, MMF, along with standard therapy, can benefit a considerable proportion of patients with inflammatory CLE. Other studies, already quoted in the Discussion, yielded promising results in patients with antimalarial-resistant discoid lupus erythematosus who were also resistant to other immunosuppressives. Thalidomide, retinoids, and dapsone are used in refractory cases, albeit with minimal evidence derived from controlled trials 9 .
KONSTANTINOS TSELIOS, MD, PhD, Centre for Prognosis Studies in the Rheumatic Diseases, University of Toronto Lupus Clinic, University Health Network; DAFNA D. GLADMAN, MD, FRCPC, Centre for Prognosis Studies in the Rheumatic Diseases, University of Toronto Lupus Clinic, University Health Network; JIANDONG SU, MB, BSc, Centre for Prognosis Studies in the Rheumatic Diseases, University of Toronto Lupus Clinic, University Health Network; MURRAY B. UROWITZ, MD, FRCPC, Centre for Prognosis Studies in the Rheumatic Diseases, University of Toronto Lupus Clinic, University Health Network, Toronto, Ontario, Canada. Address correspondence to Dr. M.B. Urowitz, University of Toronto Lupus Clinic, Centre for Prognosis Studies in the Rheumatic Diseases, Toronto Western Hospital, 399 Bathurst St., 1E-410B, Toronto, Ontario M5T 2S8, Canada. E-mail: m.urowitz@utoronto.ca

\section{REFERENCES}

1. Bachmeyer C, Galmiche S, Fayand A, Degachy A, Georgin-Lavialle $\mathrm{S}$. Mycophenolate mofetil in refractory cutaneous lupus erythematosus: no definitive evidence. J Rheumatol 2016;43:1766-7.

2. Tselios K, Gladman DD, Su J, Urowitz MB. Mycophenolate mofetil in nonrenal manifestations of systemic lupus erythematosus: an observational cohort study. J Rheumatol 2016;43:552-8.

3. Jallouli M, Galicier L, Zahr N, Aumaître O, Francès C, Le Guern V, et al; Plaquenil Lupus Systemic Study Group. Determinants of hydroxychloroquine blood concentration variations in systemic lupus erythematosus. Arthritis Rheumatol 2015;67:2176-84.

4. Mok CC, Penn HJ, Chan KL, Tse SM, Langman LJ, Jannetto PJ. Hydroxychloroquine serum concentrations and flares of systemic lupus erythematosus: a longitudinal cohort analysis. Arthritis Care Res 2016 Jan 8 (E-pub ahead of print).

5. Chasset F, Arnaud L, Costedoat-Chalumeau N, Zahr N, Bessis D, Francès $\mathrm{C}$. The effect of increasing the dose of hydroxychloroquine (HCQ) in patients with refractory cutaneous lupus erythematosus (CLE): an open-label prospective pilot study. J Am Acad Dermatol 2016;74:693-9.

6. Rainsford KD, Parke AL, Clifford-Rashotte M, Kean WF. Therapy and pharmacological properties of hydroxychloroquine and chloroquine in treatment of systemic lupus erythematosus, rheumatoid arthritis and related diseases. Inflammopharmacology 2015;23:231-69.

7. Rúa-Figueroa Í, Richi P, López-Longo FJ, Galindo M, Calvo-Alén J, Olivé-Marqués A, et al. Comprehensive description of clinical characteristics of a large systemic lupus erythematosus cohort from the Spanish Rheumatology Society Lupus Registry (RELESSER) with emphasis on complete versus incomplete lupus differences. Medicine 2015;94:e267.

8. Bruce IN, O'Keeffe AG, Farewell V, Hanly JG, Manzi S, Su L, et al. Factors associated with damage accrual in patients with systemic lupus erythematosus: results from the Systemic Lupus International Collaborating Clinics (SLICC) Inception Cohort. Ann Rheum Dis 2015;74:1706-13.

9. Chang AY, Werth VP. Treatment of cutaneous lupus. Curr Rheumatol Rep 2011;13:300-7.

J Rheumatol 2016;43:9; doi:10.3899/jrheum.160749 